\title{
Screening of Alginate Lyase-Producing Bacteria and Optimization of Media Compositions for Extracellular Alginate Lyase Production
}

\author{
Hadis Tavafi ${ }^{1}$, Ahya Abdi- Ali $^{* 1}$, Parinaz Ghadam ${ }^{2}$ and Sara Gharavi ${ }^{2}$ \\ ${ }^{1}$ Department of Microbiology, Faculty of Biological Sciences, Alzahra University, Tehran, Iran; ${ }^{2}$ Department of \\ Biotechnology, Faculty of Biological Sciences, Alzahra University, Tehran, Iran
}

Received 5 November 2015; revised 14 February 2016; accepted 15 February 2016

\begin{abstract}
Background: Alginate is a linear polysaccharide consisting of guluronate (polyG) and mannuronate (polyM) subunits. Methods: In the initial screening of alginate-degrading bacteria from soil, 10 isolates were able to grow on minimal medium containing alginate. The optimization of cell growth and alginate lyase (algL) production was carried out by the addition of $0.8 \%$ alginate and $0.2-0.3 \mathrm{M} \mathrm{NaCl}$ to the culture medium. Of 10 isolates, one was selected based on its fast growth rate on minimal 9 medium containing $0.4 \%$ sodium alginate. The selected bacterium, identified based on morphological and biochemical characteristics, as well as 16S rDNA sequence data, was confirmed to be an isolate belonging to the genus Bacillus and designated as Bacillus sp. TAG8. Results: The results showed the ability of Bacillus sp. TAG8 in utilizing alginate as a sole carbon source. Bacillus sp. TAG8 growth and algL production were augmented with an increase in sodium alginate concentration and also by the addition of $0.2-0.3 \mathrm{M} \mathrm{NaCl}$. Molecular analysis of TAG8 algL gene showed $99 \%$ sequence identity with algL of Pseudomonas aeruginosa PAO1. The algL produced by Bacillus sp. TAG8 cleaved both polyM and polyG blocks in alginate molecule, as well as acetylated alginate residues, confirming the bifunctionality of the isolated lyase. Conclusion: The identification of novel algL genes from microbial communities constitutes a new approach for exploring lyases with specific activity against bacterial alginates and may thus contribute to the eradication of persistent biofilms from clinical samples. DOI: 10.6091/.21.1.48
\end{abstract}

Keywords: Alginate, Bacillus spp., Alginate lyase, Pseudomonas biofilm

Corresponding Author: Ahya Abdi-Ali

Department of Microbiology, Faculty of Biological Sciences, Alzahra University, Tehran, Iran; Tel: (+98-21) 88044052; Fax: (+98-21) 88058912;

E-mail: abdialya@alzahra.ac.ir

\section{INTRODUCTION}

A lginate, a linear unbranched heteropolysaccharide, is composed of (1-4)-linked $\beta$ D-mannuronate $(\mathrm{M})$ and $\alpha$-L-guluronate $(\mathrm{G})$, which are arranged by glycosidic bonds as a polyM block, a polyG block, and a random polyMG block ${ }^{[1,2]}$. The relative amount and distribution of these two residues vary with species and growth conditions ${ }^{[3]}$.

Alginate is produced by brown algae and some bacteria belonging to the genera Azotobacter, as well as several species of Pseudomonas ${ }^{[4]}$ and is also found in acetylated and non-acetylated forms. Alginate produced by brown seaweeds is not acetylated but some of the $\mathrm{M}$ residues in bacterial alginates may be
O-acetylated on the 2 and/or 3 positions of $\mathrm{D}$ mannuronate ${ }^{[5]}$. The acetylated form of alginate is synthesized by certain bacteria, such as mucoid cells of Pseudomonas aeruginosa and Azotobacter vinelandii. $P$. aeruginosa causes serious chronic pulmonary infections in the lungs of patients with cystic fibrosis, and the alginate produced by bacterial cells seems to play a crucial role in the adherence of the bacterium to target cells and biofilm formation ${ }^{[6]}$. Due to the contribution of alginate to the formation of mucoid biofilm structure, its function in bacterial virulence, and its role in the persistent nature of lung infections, alginate has long been considered as an important therapeutic target ${ }^{[7]}$. Biofilms prevent effective antibiotics treatment and decrease the uptake and the 
early bactericidal effect of aminoglycoside antibiotics, thus making treatment of biofilm-dependent bacterial infectious diseases difficult. This feature makes the alginate as an important virulence factor in infections ${ }^{[8]}$. P. aeruginosa has been used as a model in genetic studies of bacterial alginate biosynthesis since all $P$. aeruginosa strains have been shown to carry the genes that encode the regulatory and biosynthetic machinery for alginate production ${ }^{[9]}$.

Alginates are enzymatically depolymerized by alginate lyases (algLs), which catalyze the degradation of the glycosidic bonds between D-mannuronate and L-guluronate by $\beta$-elimination and generate a product containing 4-deoxy-L-erythro-hex-4enopyrano-syluronic acid as the non-reducing terminal end $^{[10]}$. algLs are classified into three groups by their substrate specificity: the first type is specific toward $G$ block (EC4.2.2.11), the second type is specific toward $\mathrm{M}$ block (EC4.2.2.3), and the third type is bifunctional for $\mathrm{G}$ and $\mathrm{M}$ blocks. Those alginates specific to $\mathrm{G}$ or $\mathrm{M}$ blocks are called monofunctional algLs, while those specific to MG blocks are called bifunctional algLs ${ }^{[11]}$.

algLs are found both in non-alginate synthesizing and alginate synthesizing organisms. In the nonalginate synthesizing organisms, algLs play important roles in the absorption of alginate as a carbon source ${ }^{[12]}$. In this case, microorganisms are dependent on the depolymerization activity of algL. In general, microorganisms that grow on alginate secrete extracellular algLs to degrade alginate and then transport the degraded product into the cell for assimilation via cellular metabolism ${ }^{[13]}$. Although some strains express algL activities constitutively, most bacterial extracellular algLs exhibit their activities only when the host cells are cultivated in the presence of alginate $^{[11]}$. algLs are produced by a number of microorganisms, including marine algae, marine molluscs, fungi, bacteria, bacteriophages, and viruses $^{[14]}$. Gram-positive bacteria such as Bacillus circulans and Gram-negative bacteria like Azotobacter vinelandii, Klebsiella aerogenes, K. pneumonia, Pseudomonas maltophilia, $P$. putida, and $P$. laeruginosa have also been reported to produce algLs ${ }^{[15]}$. Although decomposition of alginate by microorganisms appears to be carried out almost entirely by eubacteria, few Gram-positive bacteria have been identified as the producers of algL ${ }^{[16]}$. Among alginate biofilm-producing bacteria, $P$. aeruginosa is a clinically important pathogene.. Furthermore, alginate biofilm is a crucial virulence factor in lung infections by this bacterium. algL removes exopolysaccharide from the surface of mucoid Pseudomonal cells in vivo and in vitro and inhibits the adherence of the mucoid strain of $P$. aeruginosa, as well as promotes the diffusion of aminoglycosides through the extracellular polysaccharide of mucoid $P$. aeruginos ${ }^{[17]}$. Therefore, the lyase can be used as an adjuvant therapeutic agent for the treatment of infection by mucoid strains of $P$. aeruginosa. algL has also a potential application for enhancing the bacteriocidal effects of antibiotics against mucoid $P$. aeruginosa in biofilms ${ }^{[18]}$.

Considering the enzymatic treatment of infections caused by biofilm-forming bacteria, a search was carried out for a new algL from soil bacteria ${ }^{[19]}$. Moreover, genetic studies on algL-producing microorganisms have revealed that the algL genes are clustered with other alginate biosynthetic gene loci ${ }^{[20]}$. Hence, in the present study and based on the presence of algL gene, an algL-producing bacterium named Bacillus sp. TAG8 was isolated from soil. In order to increase the production yield of algL by the selected isolate, cell growth and conditions for enzyme production were optimized on the basis of various concentrations of alginate and $\mathrm{NaCl}$. The extracellular bifunctional alginate lyase produced by Bacillus sp. TAG8 was analyzed based on its interaction with nonacetylated and acetylated alginate.

\section{MATERIALS AND METHODS}

\section{Screening of alginate lyase-producing bacteria}

To isolate alginate-degrading bacteria, $1.0 \%$ sodium alginate solution was poured over specified $100 \mathrm{~cm}^{2}$ areas of soil once a week for three months ${ }^{[19]}$. In addition, another area of the soil was sampled directly (without alginate solution). In both methods, about $1 \mathrm{~g}$ of the soil samples was mixed with $10 \mathrm{~mL}$ sterilized saline solution and shaked. Then the supernatant fluid was filtered and cultured on agar medium containing $0.5 \%$ alginate. Medium for the initial isolation of bacteria consisted of $0.5 \%$ sodium alginate, $1.0 \%$ peptone, $0.5 \%$ yeast extract, $0.5 \% \mathrm{NaCl}$, and $1.5 \%$ agar (pH 7.0). Bacteria were incubated at $37^{\circ} \mathrm{C}$ for $48 \mathrm{~h}$. To confirm the capability of alginate utilization by the isolated bacteria, colonies from both screening methods were cultured on minimal 9 (M9) agar medium containing $0.2,0.4,0.6$, and $0.8 \%(\mathrm{w} / \mathrm{v})$ sodium alginate. The selection criteria of the colonies were rapid growth (in $24 \mathrm{~h}$ ) in the lowest concentration of sodium alginate. A colony with the fastest growth rate on the M9 medium containing $0.4 \%$ sodium alginate was selected for further studies. Isolated bacterium was cultured in M9 medium and LuriaBertani (LB) broth to investigate the effects of alginate and $\mathrm{NaCl}$ on the cell growth and alginate lyase production. 


\section{Biochemical and molecular characterization of the isolated strain}

The selected bacterium was isolated by standard dilution plating methods on M9 agar medium consisting of 0.4 to $0.8 \%(\mathrm{w} / \mathrm{v})$ alginate at $37^{\circ} \mathrm{C}$. For identification of the isolate, Gram staining procedure and the following biochemical tests were carried out: oxidase, catalase, Voges-Proskauer, indol and $\mathrm{H}_{2} \mathrm{~S}$ formation, hydrolysis of starch, gelatin, esculin, phenyl alanine and casein, nitrate reduction and acid formation of glucose, sucrose, lactose, and hemolysis test $^{[21]}$.

For molecular identification, the isolate was incubated in a $\mathrm{LB}$ broth at $37^{\circ} \mathrm{C}$ overnight. The cells were harvested by centrifugation and the genomic DNA was extracted using PCR template purification kit (Kiagen, Iran). The amplification of $16 \mathrm{~S}$ rDNA fragments was performed by thermal cycles as: an initial denaturation at $95^{\circ} \mathrm{C}$ for $10 \mathrm{~min}$, followed by 35 cycles of denaturation at $94^{\circ} \mathrm{C}$ for $60 \mathrm{~s}$, annealing at $58^{\circ} \mathrm{C}$ for $30 \mathrm{~s}$, extension at $72^{\circ} \mathrm{C}$ for $60 \mathrm{~s}$, and a final extension at $72^{\circ} \mathrm{C}$ for $10 \mathrm{~min}$. Primers used are shown in Table 1.

Due to the importance of finding new algLs that could be effective on $P$. aeruginosa biofilms, the criteria for bacteria selection were based on the ability to degrade alginate as the sole carbon source, as well as to carry the $\operatorname{alg} L$ gene. The sequence for this gene (NCBI Reference Sequence: NC_002516.2) was used as a template to design forward and reverse primers (Table 1). PCR amplification was performed using extracted genomic DNA as a template with the following program: initial denaturation at $94^{\circ} \mathrm{C}$ for 5 min, followed by 35 cycles of denaturation at $94^{\circ} \mathrm{C}$ for $30 \mathrm{~s}, 63^{\circ} \mathrm{C}$ for $50 \mathrm{~s}, 72^{\circ} \mathrm{C}$ for $95 \mathrm{~s}$, and a final extension at $72^{\circ} \mathrm{C}$ for $10 \mathrm{~min}$. PCR products were then extracted from the gel by Gel/PCR DNA Isolation System kit (Viogene, Taiwan) and sequenced (Macrogen, Korea). The $16 \mathrm{~s}$ rDNA sequences and $\operatorname{algL}$ gene were aligned with multiple sequences from databases in NCBI Database using Blastn. The phylogenetic tree was constructed using neighbor-joining algorithms (Mega 5).
Effect of alginate and $\mathrm{NaCl}$ concentrations on cell growth and alginate lyase activity

In order to evaluate the effect of sodium alginate and $\mathrm{NaCl}$ on cell growth and extracellular lyase activity, Bacillus sp. TAG8 was cultured in M9 and LB broth containing 0.2 to $0.8 \%$ sodium alginate as well as in M9 and $\mathrm{LB}$ broth containing 0.1 to $0.5 \mathrm{M} \mathrm{NaCl}$ (3 replicates per treatment) at $180 \mathrm{rpm}$ at $37^{\circ} \mathrm{C}$ for $18 \mathrm{~h}$. During incubation (3 hours), samples were withdrawn periodically, and the optical density in each treatment was measured at $600 \mathrm{~nm}$ to assess the growth rate. Bacterial growth curve was subsequently plotted. In addition to assaying the enzyme activity from the treated media, the cell pellets were centrifuged at 4000 $\times \mathrm{g}$ at $4^{\circ} \mathrm{C}$ for $10 \mathrm{~min}$ to obtain supernatant (as a source of enzyme) to estimate the extracellular algL activity.

\section{Extracellular alginate lyase activity assay}

For measurement of the enzymatic activity of algL, $0.2 \mathrm{ml}$ of supernatant was added to $1 \mathrm{ml}$ of $1.0 \mathrm{M}$ Tris$\mathrm{HCl}$ buffer ( $\mathrm{pH} 8.3$ ) containing $0.1 \%$ sodium alginate as substrate and incubated at $30^{\circ} \mathrm{C}$ for $5 \mathrm{~min}$. Next, the reaction was stopped by heating in boiling water for 5 min. The enzyme activity was assayed by measuring the increase in absorbance at $235 \mathrm{~nm}$, which is a result of double bond formation at the non-reducing end by $\beta$-elimination reaction. Furthermore, deoxy sugar formation in the supernatant was determined by tiobarbitoric acid (TBA) method at $548 \mathrm{~nm}^{[4,15]}$. The results are represented as enzyme units, where one unit of enzyme activity is defined as the amount of enzyme that generates $1 \mathrm{nmol}$ of $\beta$-formyl-pyruvate per min per $\mathrm{ml}$ at $37^{\circ} \mathrm{C}^{[15]}$.

\section{Substrate specificity of the enzyme}

In order to study the substrate specificity of the enzyme isolated from Bacillus sp. TAG8, polyM and polyG blocks of alginate were used as substrates. The blocks were prepared by mild acid hydrolysis of alginate as described by Kashima and $\operatorname{Imai}^{[22]}$, and the chemical composition of the blocks was determined by H-NMR analysis. Finally, the optimal enzymatic

Table 1. Primers used for determining nucleotide sequences of $16 \mathrm{~S}$ rDNA and the $\operatorname{alg} L$ gene from Bacillus sp. TAG8 genomic DNA.

\begin{tabular}{lll}
\hline Primer & Sequence (5 to 3) & Use \\
\hline $27 \mathrm{~F}$ & AGAGTTTGATCCTGGCTCAG & Amplification of 16S rDNA gene \\
$492 \mathrm{R}$ & GGCTACCTTGTTACGACTT & \\
& & \\
AlgL F & ATGAAAACGTCCCACCTGATCCG & Amplification of alginate lyase gene \\
AlgL R & TCAACTTCCCCCTTCGCGGC & \\
\hline
\end{tabular}


activity was measured using the TBA method ${ }^{[23]}$ in optimal concentrations of $0.3 \mathrm{M} \mathrm{NaCl}$ and $0.8 \%$ sodium alginate for $12 \mathrm{~h}$ of incubation time.

\section{Statistical analysis}

Optimum conditions for cell growth (absorbance at $600 \mathrm{~nm}$ ) and algL production assay (absorbance at 235 and/or $548 \mathrm{~nm}$ ) were established, and the results were analyzed statistically. Significant differences were determined by one-way analysis of variance (ANOVA one-way) with pairwise comparisons using Tukey's method. A $P$ value $<0.05$ was considered statistically significant. Statistical analysis was performed using the Prism5 software.

\section{RESULTS AND DISCUSSION}

For the isolation of algL-producing bacterium, an initial screening was performed on M9 agar plate containing $0.4 \%(\mathrm{w} / \mathrm{v})$ sodium alginate as the sole carbon source. After incubation at $37^{\circ} \mathrm{C}$ for $48 \mathrm{~h}, 10$ colonies appeared on the agar plate with algL activity. Interestingly, no difference was observed in the diversity of the isolated bacteria from sprayed soil samples with or without sodium alginate solution. However, Nakagawa et al. ${ }^{[19]}$ have reported that treatment with sodium alginate solution is an effective method for the isolation of lyase-producing microorganisms. Most of the colonies were creamcolored, pale yellow, and wrinkled but some of them were flat. These isolates showed a better growth on plates containing 0.6 and $0.8 \%$ alginate; however, no growth was observed in the medium containing $0.2 \%$ and $0 \%$ sodium alginate. Based on the relative size of colonies on M9 agar medium containing $0.4 \%(\mathrm{w} / \mathrm{v})$ sodium alginate, one colony with the fastest growth rate (in 24-h incubation) was selected for further study and analyzed by PCR for the desired algL gene. Bacillus sp. TAG8 colonies were cream-colored and classified as Gram-positive bacterium with characterized biochemical properties (Table 2). The growth temperature range was $27-37^{\circ} \mathrm{C}$, and the optimal growth temperature in LB or M9 broth media was $37^{\circ} \mathrm{C}$. Other isolated colonies showed lower growth rates at $37^{\circ} \mathrm{C}$, as compared to Bacillus sp. TAG8. Based on the biochemical properties, Bacillus sp. TAG8 isolate showed $>79 \%$ similarity to Bacillus species (http: //www. microrao. com /identify. html and http://www.tgw1916.net/bacteria_abis.html). For the precise identification of Bacillus sp. TAG8, the $16 \mathrm{~S}$ rDNA sequence was determined and analyzed using Blastn. Homology studies revealed that $16 \mathrm{~S}$ rDNA gene of the strain TAG8 showed sequence identities of $99 \%$ with Bacillus atrophaeus strain
NXUSASNFB001, Bacterium NS7, Bacillus atrophaeus strain AECSB18, Bacillus methyltrophicus strain LH-T8, Bacillus pumilus strain 3L0-10E, Basillus sp. SDHR2 and 98\% with the strain Bacillus sp. 13422.

The phylogenetic tree was constructed using the neighbor-joining method on the basis of the comparative sequence analysis of 16S rDNA (Fig. 1). Based on the evaluation of biochemical, morphological, and physiological characteristics and $16 \mathrm{~S}$ rDNA sequence analysis, it is concluded that TAG8 belongs to the genus Bacillus and is named Bacillus sp. TAG8. The nucleotide sequence of the 16S rDNA of Bacillus sp. TAG8 was submitted to GenBank (accession number KR267304).

One important aspect of this study is to ultimately find an $\operatorname{algL}$ that can be effective in the elimination of $P$. aeruginosa biofilm. In this study, the presence of algL gene was important in the screening of bacteria. The primers were designed to facilitate the screening (Table 1). Bacillus sp. TAG8 genomic DNA was used as template for PCR amplification of the $\operatorname{algL}$ gene. PCR product of the gene was 1104 bp (Fig. 2). Furthermore, the subsequent blast analysis on algL gene showed that the closest relative of the Bacillus sp. TAG8 was $P$. aeruginosa PAO1 (99\%). The algL sequence of Bacillus sp. TAG8 was submitted to GenBank (accession number KR267305).

In order to study the relationship between cell growth and algL production, Bacillus sp. TAG8 was cultured

Table 2. Biochemical properties of the Bacillus sp. TAG8

\begin{tabular}{lc}
\hline Properties & Bacillus sp. TAG8 \\
\hline Gram stain & + \\
Shape & Rods \\
Spore & + \\
Motility & + \\
Pigmentation & cream/dark cream \\
Enzyme activity of: & \\
Oxidase & - \\
Catalase & + \\
VP test & + \\
Indole & - \\
$\mathrm{H}_{2} \mathrm{~S}$ formation & - \\
Hydrolysis of: & \\
Starch & + \\
Gelatin & + \\
Esculin & + \\
Phenyl alanine & - \\
Casein & - \\
Nitrate reduction & + \\
Acid formation of: & + \\
Glucose & \\
Sucrose & + \\
Lactose & + \\
Hemolysis & - \\
\hline
\end{tabular}




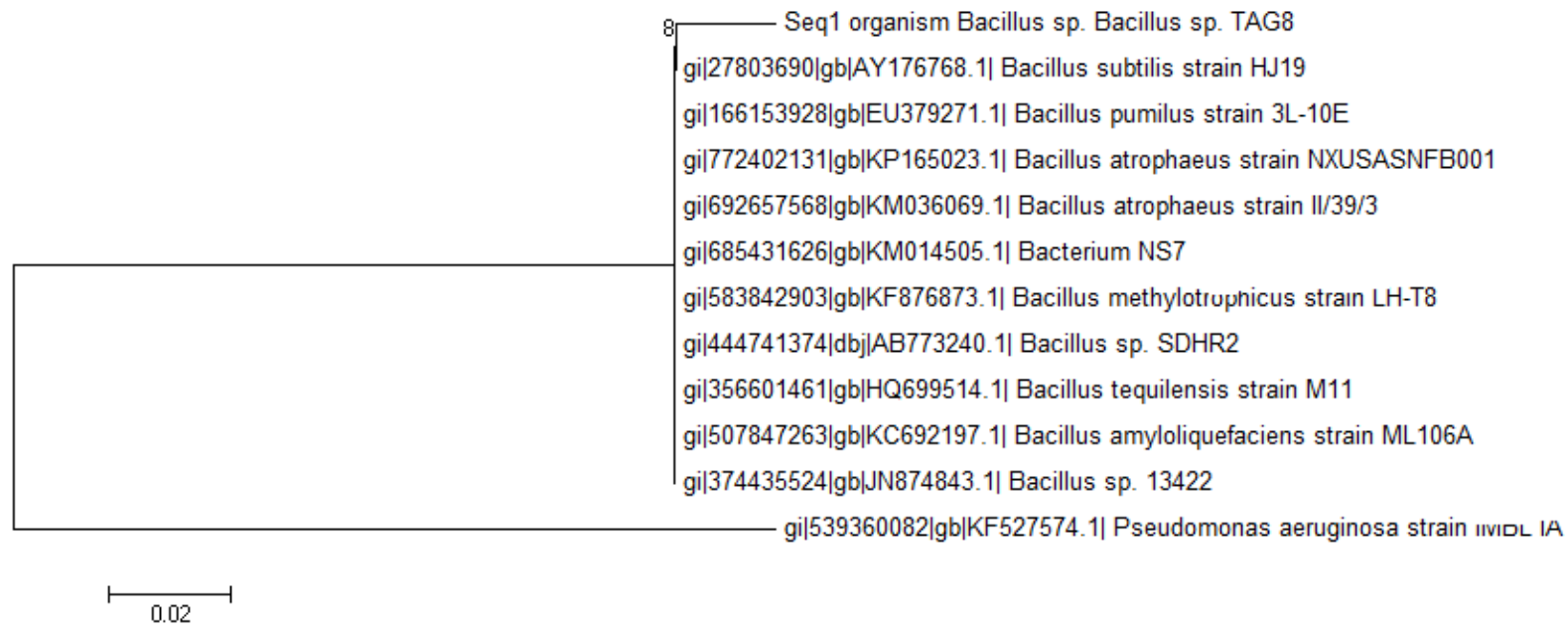

Fig. 1. Phylogenetic analysis based on the $16 \mathrm{~S}$ rDNA sequences from Bacillus sp. TAG8 and eleven other bacteria. Neighbourjoining model was employed for the tree construction, and bootstrap values were obtained with 1000 repetitions. The bar labeled 0.02 indicates 2 base changes per 100 nucleotides.

on M9 and LB broth medium containing sodium alginate and $\mathrm{NaCl}$. As expected, growth was inhibited when M9 broth medium without carbon source was used. However, growth in the presence of sodium alginate clearly indicates that Bacillus sp. TAG8 is capable of using alginate as the sole carbon source. Faster growth rates and the appearance of colonies were observed at low concentrations of alginate $(0.4 \%)$. Park et al. ${ }^{[24]}$ isolated strain MJ-3 and reported that the growth rate of the isolate is significant in M9 medium containing $0.8 \%$ alginate. However, the growth rates of the isolates were increased with higher sodium alginate concentrations in LB broth (Fig. 3A). Therefore, this medium was used for the optimization of algL production.

In addition to the study of various alginate concentrations on bacterial growth, the effect of different concentrations of $\mathrm{NaCl}(0.1-0.5 \mathrm{M})$, as a supplement, was also investigated. The results showed that the concentrations of 0.2 and $0.3 \mathrm{M} \mathrm{NaCl}$ improved the bacterial growth compared to 0.4 and 0.5 $\mathrm{M} \mathrm{NaCl}$; however, higher $\mathrm{NaCl}$ concentrations did not increase the cell growth rate (Fig. 3B).

algL activity has been determined by various methods ${ }^{[1,15,24,25]}$. This enzyme depolymerizes alginate by $\beta$-elimination reaction to produce 4 deoxy-erytrohex-4-enopyranuronosyl groups at non-reducing end ${ }^{[1]}$. Among assays to measure extracellular algL activity, ultraviolet absorption method, in which the absorbance at $235 \mathrm{~nm}$ is measured for the supernatant ${ }^{[24]}$, is prevalent. Muramatsu ${ }^{[26]}$ has reported that for the measurement of the kinetic parameters of enzymatic reaction, this assay has been proven to be both simple and rapid. The absorbance at $235 \mathrm{~nm}$ reflects the production of unsaturated uronates ${ }^{[27]}$. In the current study, in addition to measuring the enzyme activity at $235 \mathrm{~nm}$, an accurate and a quantitative TBA method were also used to measure the enzyme activity.

As Bacillus sp.TAG8, isolated in this study, is an extracellular algL producing bacterium, algL activity was assessed in the supernatant of the bacterial

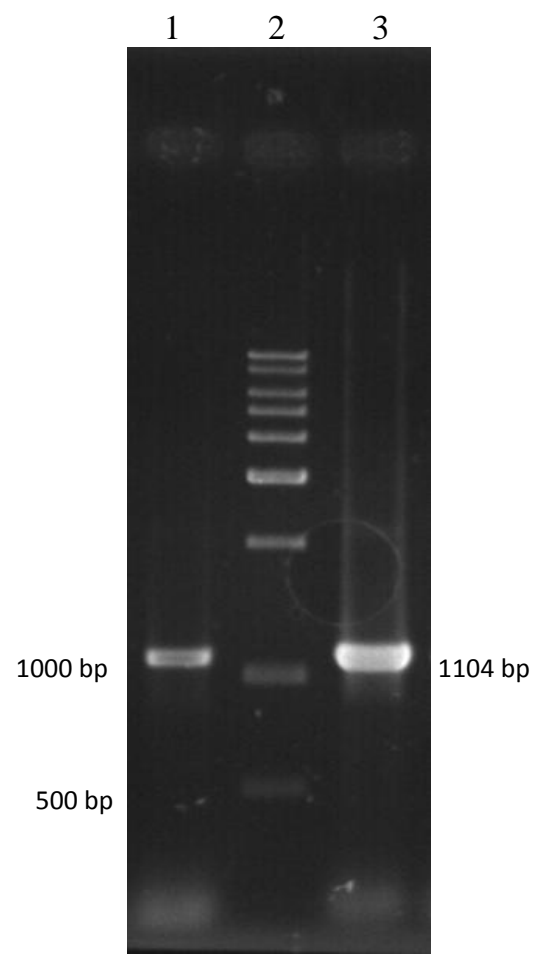

Fig. 2. PCR product algL gene amplification from PAO1 and TAG8. Lane 1, Bacillus sp. TAG8; Lane 2, molecular weight standard (10 kbp, Fermentase, Lithuania); Lane 3, PAO1 strain. 

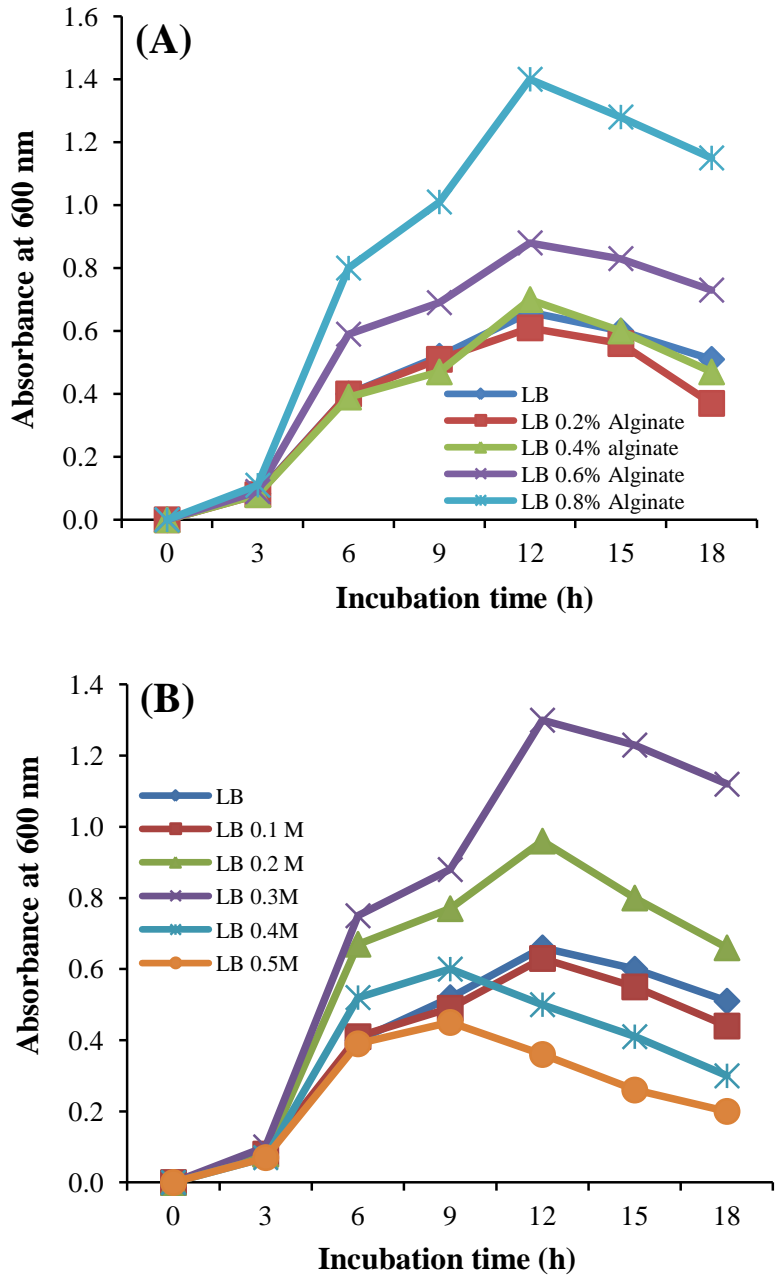

Fig. 3. Growth curve of Bacillus sp. TAG8 on Luria-Bertani medium containing various concentrations of alginate $(\mathrm{A})$ and various amounts of $\mathrm{NaCl}(\mathrm{B})$ at $180 \mathrm{rpm}, 18 \mathrm{~h}$ incubation time and $37^{\circ} \mathrm{C}$.

culture containing different concentrations of sodium alginate and $\mathrm{NaCl}$. The results showed that the levels of enzyme activity increased significantly with increase in the alginate concentration $(P<0.05)$ (Fig. 4A). However, algL activity did not increase in 0.4 and 0.5 $\mathrm{M} \mathrm{NaCl}$ concentrations compared to 0.2 and $0.3 \mathrm{M}$ $\mathrm{NaCl}$ (Fig. 4B). Eftekhar and Schiller ${ }^{[15]}$ studied the effect of $\mathrm{NaCl}$ concentrations on lyase activity of $P$. aeruginosa and concluded that increasing the $\mathrm{NaCl}$ concentration can not elevate the algL production yeild.

Effects of sodium alginate and $\mathrm{NaCl}$ concentrations on the growth rate of bacteria were studied simultaneously. The results showed that medium containing $0.8 \%$ sodium alginate and $0.3 \mathrm{M} \mathrm{NaCl}$ stimulated bacterial growth almost 1.2-fold more than when cultures were treated separately, and almost 2.3fold more than when bacteria were grown in LB medium without alginate $(P<0.05)$ (Fig. 5A). These results suggest that Bacillus sp.TAG8 is able to use $\mathrm{NaCl}$ as a co-factor for the degradation of the alginate in its metabolic pathway. Results also indicate that the simultaneous presence of $\mathrm{NaCl}$ and sodium alginate increased the algL activity significantly, as compared to the control LB or individually added salts $(P<0.05)$ (Fig. 5B). Furthermore, the enzymatic activity of algL was 10.5 enzymatic units in optimum conditions, demonstrating an almost 2-fold increase as compared to $0.8 \%$ alginate and $0.3 \mathrm{M} \mathrm{NaCl}$ treatments. Bacterial growth curve analysis showed that the algL activity of Bacillus sp.TAG8 continuously increased up to the stationary phase and gradually decreased, which indicates that lyase activity was related to cell growth. Park and coworkers ${ }^{[24]}$ have presented data that supports our results.
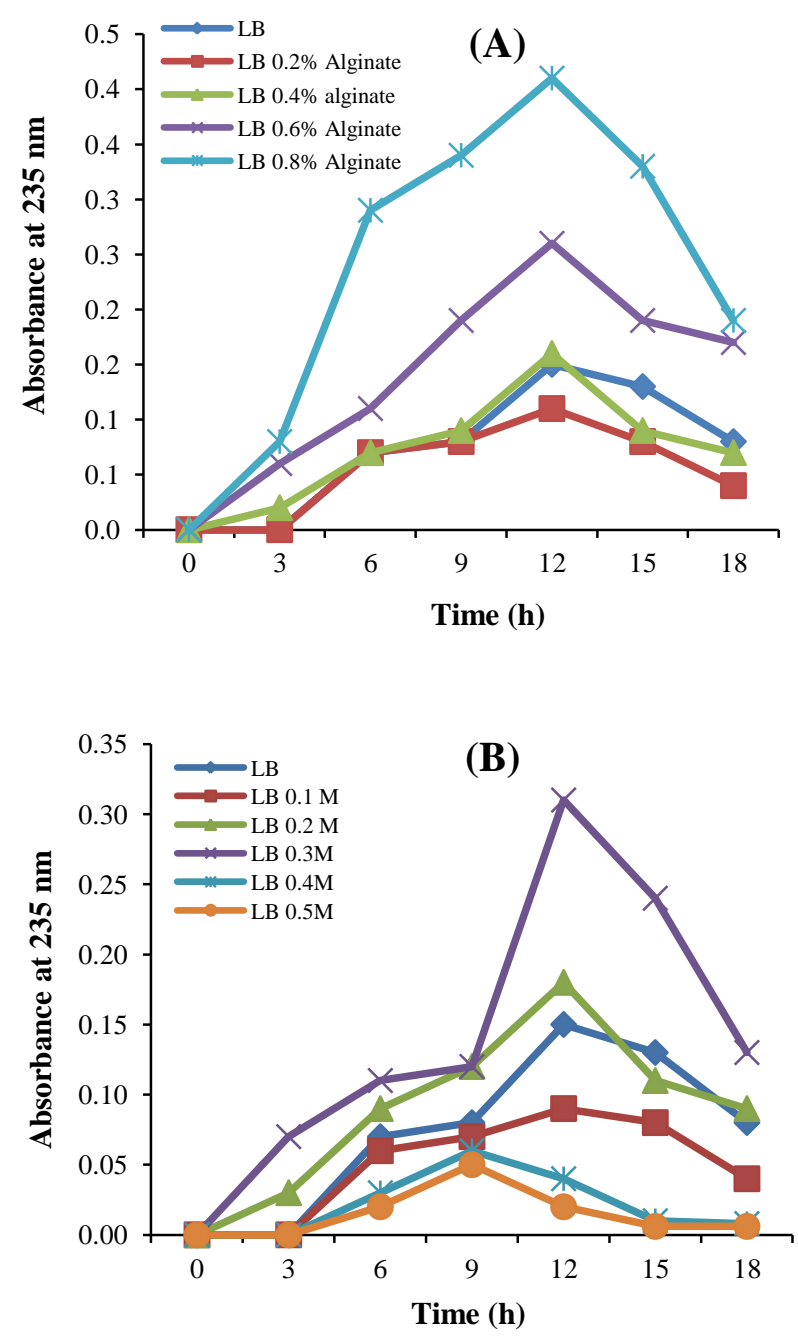

Fig. 4. Alginate lyase activity of Bacillus sp. TAG8 was grown on LB medium containing different concentrations of alginate (A) and $\mathrm{NaCl}$ (B). At 18 hours of incubation at $37^{\circ} \mathrm{C}$, the alginate lyase activity was measured based on the increase in absorbance at $235 \mathrm{~nm}$. 

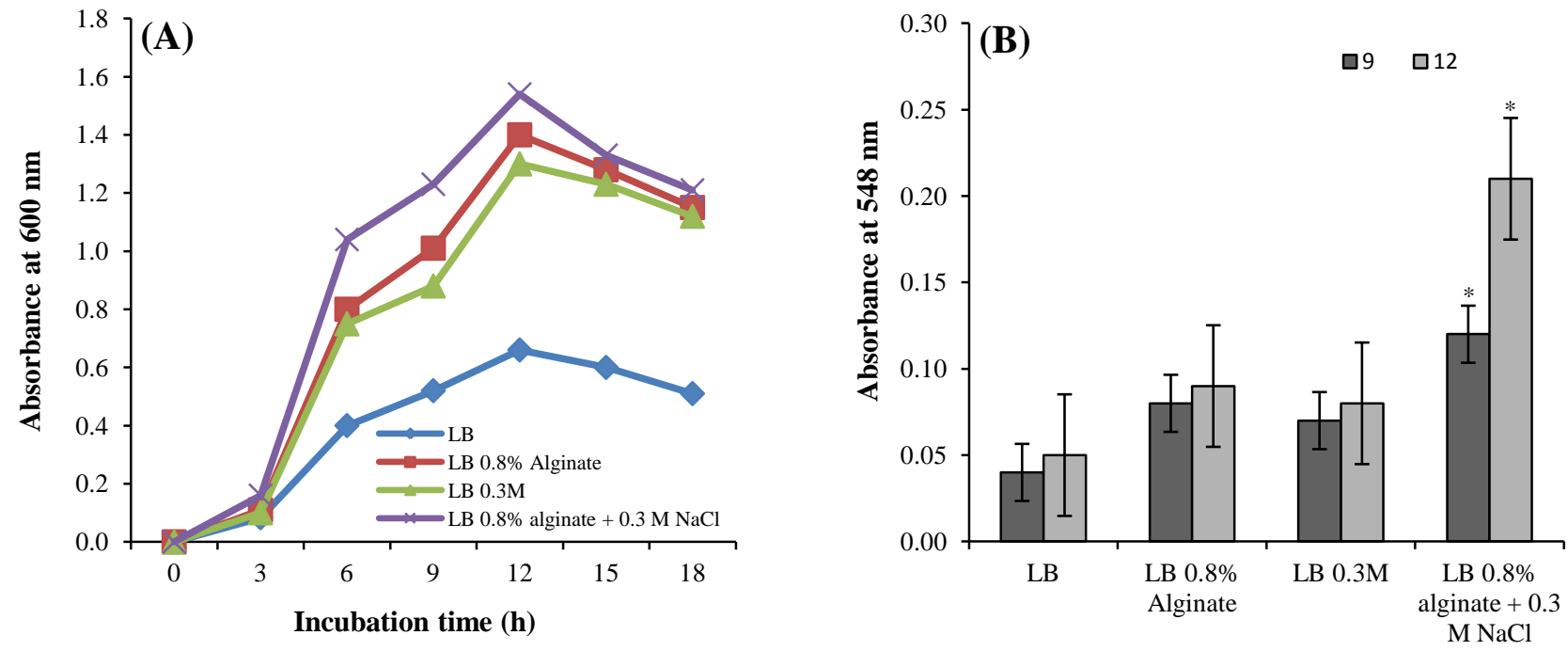

Fig. 5. The growth curve of Bacillus sp. TAG8 on LB medium containing $0.8 \%$ alginate $+0.3 \mathrm{M} \mathrm{NaCl}$ and LB medium containing $0.8 \%$ alginate and $0.3 \mathrm{M} \mathrm{NaCl}$ in 18 hours of incubation at $37^{\circ} \mathrm{C}(\mathrm{A})$ and alginate lyase activities of Bacillus sp. TAG8 grown in LB medium containing $0.8 \%$ alginate $+0.3 \mathrm{M} \mathrm{NaCl}$ and $\mathrm{LB}$ medium containing $0.8 \%$ alginate and $0.3 \mathrm{M} \mathrm{NaCl}(\mathrm{B})$. Supernatant of culteres were collected after 9 and 12 hours of incubation, and alginate lyase activity was recorded based on the increase in absorbance at 548 $\mathrm{nm}$ by TBA method. ANOVA with pairwise comparison using Tukey's method was used to compare effect of $\mathrm{NaCl}$ and sodium alginate concentrations simultaneously that showed increased alginate lyase activity significantly compared to the control LB and each treatment separately $(* P<0.05)$. Error bars indicate standard errors of mean of 4 experiments.

In the current study, lyase activity on different alginate substrates was examined to investigate the substrate specificity of the enzyme. The substrates were prepared by the partial hydrolysis of alginate as described earlier ${ }^{[22]}$. PolyM and polyG blocks were isolated, and chemical composition of each block was confirmed by H-NMR (Fig. 6). The results of lyase activity by TBA method showed that algL from Bacillus sp. TAG8 almost equally degraded polyM and polyG blocks after incubation for $12 \mathrm{~h}$. The lyase activity of TAG8 on polyM and polyG blocks was reported as the optical density of 0.2 and 0.17 at 548 $\mathrm{nm}$, respectively. One unit is defined as the release of 1 nmol $\beta$-formyl-pyruvate per minute and $10 \mathrm{nmol} \beta$ formyl-pyruvate corresponds to an absorption of 0.29 at a wavelength of $548 \mathrm{~nm}^{[15]}$. Therefore, the enzyme produced by Bacillus sp. TAG8 has been shown to be a bifunctional algL. In this context, Hansen and coworkers $^{[16]}$ identified strain $B$. circulans, which specifically degraded polyM alginate. Nakagawa et $a l .{ }^{[19]}$ also identified Bacillus sp. strain ATB-1015, which had substrate specificity for both the polyG and polyM blocks in the alginate. Moreover, Bacillus sp. TAG8 algL showed activity toward the isolated acetylated alginate of mucoid $P$. aeruginosa, indicating that this enzyme is able to degrade acetylated alginate of a pathogen source.

In this study, the growth conditions of isolated alginate-degrading bacterium, Bacillus sp. TAG8, from soil was optimized in order to achieve the higher production of algL. As the results indicate, the production and the activity of algL enhanced with an increase in growth rate, which indicats that algL production was directly related to the cell growth. Hence, as expected, the production of enzyme was increased in the logarithmic growth phase. We here assessed the roles of alginate and $\mathrm{NaCl}$ in enhancing cell growth and algL production. The results demonstrated that the Bacillus sp. TAG8 possesses an alginate-degrading system, which is assisted by $\mathrm{NaCl}$ as a metabolic co-factor for the enhanced degradation of alginate. Furthermore, the properties of TAG8 and the effect of its algL on acetylated alginate, makes Bacillus sp. TAG8 a potential candidate for further studies on the elimination of $P$. aeruginosa biofilm.

\section{ACKNOWLEDGMENTS}

This project was funded by a grant from the Alzahra University, Tehran, Iran. The authors thank Dr. Bijanzadeh from the Department of Chemistry, Kharazmi University (Tehran, Iran) for his assistance in the H-NMR analysis.

CONFLICT OF INTEREST. None declared. 

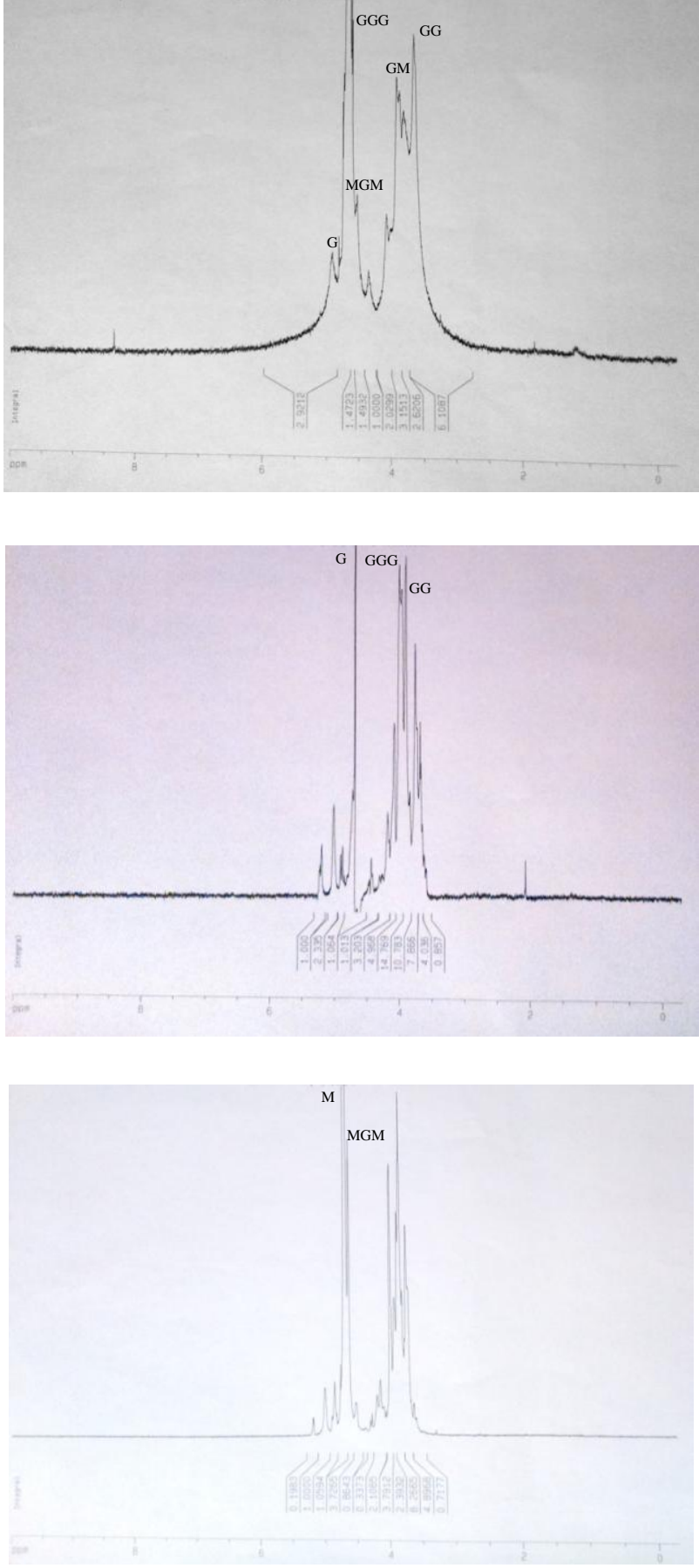

Fig. 6. The H-NMR (300 MHz) spectra of solution of (A) sodium alginate, (B) blockG (guluronate), and (C) blockM (mannuronate).

\section{REFERENCES}

1. Dong Sh, Yang J, Zhang XY, Shi M, Song XY, Chen XL, Zhang YZ. Cultivable alginate lyaseexcreting bacteria associated with the Arctic brown alga Laminaria. Marine drugs 2012; 10(11): 2481-2491.
2. Wang Y, Guo EW, Yu WG, Han F. Purification and characterization of a new alginate lyase from a marine bacterium Vibrio sp. Biotechnology letters 2013; 35(5): 703-708.

3. Gimmestad M, Ertesvåg H, Heggeset TM, Aarstad O, Svanem BI, Valla S. Characterization of three new Azotobacter vinelandii alginate lyases, one of which is involved in cyst germination. Journal of bacteriology 2009; 191(15): 4845-4853.

4. Kam N, Park YJ, Kim HS, Lee EY. Molecular identification of a polyM-specific alginate lyase from Pseudomonas sp. strain KS-408 for degradation of glycosidic linkages between two mannuronates or mannuronate and guluronate in alginate. Canadian journal of microbiology 2011; 57(12): 1032-1041.

5. Kawamoto H, Horibe A, Miki Y, Kimura T, Tanaka K, Nakagawa T, Kawamukai M, Matsuda H. Cloning and sequencing analysis of alginate lyase genes from the marine bacterium Vibrio sp. O2. Marine biotechnology 2006; 8(5): 481-490.

6. Lee SI, Choi SH, Lee EY, Kim HS. Molecular cloning, purification, and characterization of a novel polyMGspecific alginate lyase responsible for alginate $\mathrm{MG}$ block degradation in Stenotrophomas maltophilia KJ-2. Applied microbiology and biotechnology 2012; 95(6):1643-1653.

7. Ramsey DM, Wozniak DJ. Understanding the control of Pseudomonas aeruginosa alginate synthesis and the prospects for management of chronic infections in cystic fibrosis. Molecular microbiology 2005; 56(2): 309-322.

8. Hashimoto W, Miyake O, Momma K., Kawai S, Murata K. Molecular identification of oligoalginate lyase of Sphingomonas sp. strain A1 as one of the enzymes required for complete depolymerization of alginate. Journal of bacteriology 2000; 182(16): 4572-4577.

9. Muhammadi, Ahmed N. Genetics of bacterial alginate: alginate genes distribution, organization and biosynthesis in bacteria. Current genomics 2007; 8(3): 191-202.

10. Sim SJ, Baik KS, Park SC, Choe HN, Seong CN, Shin TS, Woo HC, Cho JY, Kim D. Characterization of alginate lyase gene using a metagenomic library constructed from the gut microflora of abalone. Journal of industrial microbiology and biotechnology 2012; 39(4): 585-593.

11. Matsushima R, Danno H, Uchida M, Ishihara K, Suzuki T, Kaneniwa M, Ohtsubo Y, Nagata Y, Tsuda M. Analysis of extracellular alginate lyase and its gene from a marine bacterial strain, Pseudoalteromonas atlantica AR06. Applied Microbiology and Biotechnology 2012; 86(2): 567-576.

12. Kim HS, Lee CG, Lee E. Alginate lyase: Structure, property, and application. Biotechnology and bioprocess engineering 2011; 16(5): 843-851.

13. Hashimoto W, He J, Wada Y, Nankai H, Mikami B, Murata K. Proteomics-based identification of outermembrane proteins responsible for import of macromolecules in Sphingomonas sp. A1: alginatebinding flagellin on the cell surface. Biochemistry 2005; 44(42): 13783-13794. 
14. Wong TY, Preston LA, Schiller NL. Alginate Lyase: review of major sources and enzyme characteristics, structure-function analysis, biological roles, and applications. Annual review microbiology 2000; 54: 289-340.

15. Eftekhar F, Schiller NL. Partial purification and characterization of a mannuronan-specific alginate lyase from Pseudomonas aeruginosa. Current microbiology 1994; 29(1): 37-42.

16. Hansen J B, Doubet RS, Ram J. Alginase enzyme production by Bacillus circulans. Applied and environmental microbiology 1984; 47(4): 704-709.

17. Lin X, Feng H, Zhao Y, Xin-zhi L, Wen-gong Y. A Novel alginate lyase with high activity on acetylated alginate of Pseudomonas aeruginosa FRD1 from Pseudomonas sp. QD03. World journal microbiology and biotechnology 2006; 22(1): 81-88.

18. Shin JW, Choi SH, Kim DE, Kim HS, Lee JH, Lee IS, Lee EY. Heterologous expression of an alginate lyase from Streptomyces sp. ALG-5 in Escherichia coli and its use for preparation of the magnetic nanoparticleimmobilized enzymes. Bioprocess and biosystems engineering 2011; 34(1):113-119.

19. Nakagawa A, Ozaki T, Chubachi K, Hosoyama T, Okubo T, Iyobe S, Suzuki T. An effective method for isolating alginate lyase-producing Bacillus sp. ATB1015 strain and purification and characterization of the lyase. Journal of applied microbiology 1998; 84(3): 328-335.

20. Lloret L, Barreto R, León R, Moreno S, MartínezSalazar J, Espín G, Soberón-Chávez G. Genetic analysis of the transcriptional arrangement of Azotobacter vinelandii alginate biosynthetic genes: identification of two independent promoters. Molecular microbiology 1996; 21(3): 449-457.

21. Betty AF, Daniel FS, Alice SW. Bailey \& Scott's diagnostic microbiology. $12^{\text {th }}$ Edition. United States: Mosby; 2007.

22. Kashima K, Imai M. Dominant impact of the $\alpha$-Lguluronic acid chain on regulation of the mass transfer character of calcium alginate membranes. Desalination and water treatment 2011; 34(1-3): 257-265.

23. Weissbach A, Hurwitz J. The formation of 2-keto-3deoxyheptonic acid in extracts of Escherichia coli B. I. Identification. The Journal of biological chemistry 1959; 234(4): 705-709.

24. Park HH, Kam N, Lee EY, Kim HS. Cloning and characterization of a novel oligoalginate lyase from a newly isolated bacterium Sphingomonas sp. MJ-3. Marine biotechnology journal (NY) 2012; 14(2): 189202.

25. Huang L, Zhou J, Li X, Peng Q, Lu H, Du Y. Characterization of a new alginate lyase from newly isolated Flavobacterium sp. S20. Journal of industrial microbiology and biotechnology 2013; 40(1): 113-122.

26. Muramatsu, T. A Simple and rapid determination of alginate lyase activity. Bulletin of the faculty of fisheries nagasaki university 1975; 40: 35-38.

27. Iwamoto $\mathrm{Y}$, Araki R, Iriyama $\mathrm{K}$, Oda $\mathrm{T}$, Fukuda $\mathrm{H}$, Hayashida S, Muramatsu T. Purification and characterization of bifunctional alginate lyase from Alteromonas sp. strain no. 272 and its action on saturated oligomeric substrates. Bioscience, biotechnology, and biochemistry 2001; 65(1): 133-142. 